\title{
A METHODOLOGY FOR MODELLING TRAFFIC RELATED EMISSIONS IN SUBURBAN AREAS
}

\author{
Cristian Toşa ${ }^{1}$, Dago Antov ${ }^{2}$, Gavril Köllö ${ }^{3}$, Harri Rõuk ${ }^{4}$, Marek Rannala ${ }^{5}$ \\ ${ }^{1,3}$ Dept of Infrastructures, Technical University of Cluj-Napoca, Str. Observatorului 72-74, \\ 400363 Cluj-Napoca, Romania \\ ${ }^{2,5}$ Dept of Logistics, Tallinn University of Technology, Ehitajate tee 5, 19086 Tallinn, Estonia \\ ${ }^{4}$ Dept of Road Engineering, Tallinn University of Technology, Ehitajate tee 5, 19086 Tallinn, Estonia
}

Submitted 30 May 2012; accepted 14 February 2013; first published online 16 October 2013

\begin{abstract}
A methodology that integrates a computer program COPERT III for calculation of traffic emissions estimates, and a transportation modelling software CUBE VOYAGER was used to assess pollutant emissions for a suburban area, as a support for future transport planning strategies to be applied for any developing road network. COPERT III is used to obtain the carbon monoxide emission factors by accounting for the car fleet composition, characteristics and average speed. An aggregated emission parametric equation was determined and used further on for estimating network carbon monoxide emissions based upon the output of macroscopic traffic characteristics enabled by traffic simulation software, CUBE VOYAGER. The methodology and modelling results are applied here for Floreşti, a satellite town of Cluj-Napoca, Romania.
\end{abstract}

Keywords: traffic emission estimates; COPERT; CUBE VOYAGE; macroscopic modelling; aggregated emission parametric equation; transportation planning.

\section{Introduction}

The environmental effects of road transport include air pollution, pollution of natural drainage systems, noise pollution and energy consumption. Air pollution caused by road traffic in urban areas continues to be a cause of concern in consideration to environmental impacts and health (Brown, Affum 2002).

Road transport vehicles are commonly known as a significant contributor of atmospheric emission of numerous greenhouse gases ( $\mathrm{GHG}$ ) including carbon dioxide $\left(\mathrm{CO}_{2}\right)$, methane $\left(\mathrm{CH}_{4}\right)$ and nitrous oxide $\left(\mathrm{N}_{2} \mathrm{O}\right)$. In this respect, Nejadkoorki et al. (2008) developed a three component modelling approach for estimation of $\mathrm{CO}_{2}$ emissions for urban areas with street level resolution. Road transport also remains the major source of many local pollutant emissions that have dangerous health impact: carbon monoxide $(\mathrm{CO})$, nitrogen oxides $\left(\mathrm{NO}_{\mathrm{x}}\right)$, Nonmethane Volatile Organic Compounds (NMVOC), sulphur dioxide $\left(\mathrm{SO}_{2}\right)$ and particulate matter (PM2.5 and PM10). Emissions from road traffic are being substantially reduced by the introduction of new engine technologies; still, within urban areas the contribution from road transport is particularly high, due to a growth in passenger car traffic and motorization rate (Saija, Romano 2002). Road traffic is the dominant anthropogenic source of air pollution affecting air quality in most of the cities around the world, leading to environmental degradation especially when triggered by fast economic growth (Orru et al. 2008).

The emissions of the local pollutants from road transport strongly depend on the fuel used, engine combustion technology, exhaust after treatment devices and vehicle operating conditions. Prediction of road traffic emissions is becoming increasingly important for evaluation of environmental and transport policies and infrastructural changes or developments. The interest ranges from local road projects to large urban transport networks and even national emission inventories (Fenger 1999).

Among the pollutants resulted from road traffic, $\mathrm{CO}$ emissions were commonly used by policy makers to gauge the effectiveness of strategies to reduce air pol-

Corresponding author: Cristian Toşa

E-mail: cristian.tosa@infra.utcluj.ro 
lution from mobile sources (Flachsbart 1999). In this respect, the estimation and modelling of $\mathrm{CO}$ emissions can be a useful tool for air quality managers and environmentalists to examine different transport plans (reducing personal mobility, restructuring urban area, adopting low carbon technologies) and adopt the appropriate strategies for transportation system sustainability (O'Donoghue et al. 2007). Consequently, the approach developed for this case study deals with traffic related $\mathrm{CO}$ emissions, although it can be used for estimating other pollutants that have a major impact on the environment and human health.

In this paper, we present a methodology on how the output data of a widely used aggregated emission model (COPERT III) can be integrated into a macroscopic traffic model developed in CUBE VOYAGER in order to predict $\mathrm{CO}$ emissions for a suburban area. The methodology is then applied to a specific case in which we build the traffic model, examine the transport network and analyse future development scenarios considering environment related issues.

\section{Methodology}

In this section, we describe the modelling methodology in order to get the reader acquainted with the main sections of the developed procedure and with the constituent elements of each section. Assessing the traffic related emissions requires different tasks, ranging from problem identification, gathering basic data for the model, establishing the modelling techniques, model development and evaluation of different scenarios. We show the structure of the modelling approach in Fig. 1, in which we emphasize the main sections as well as their way of interacting with each other.

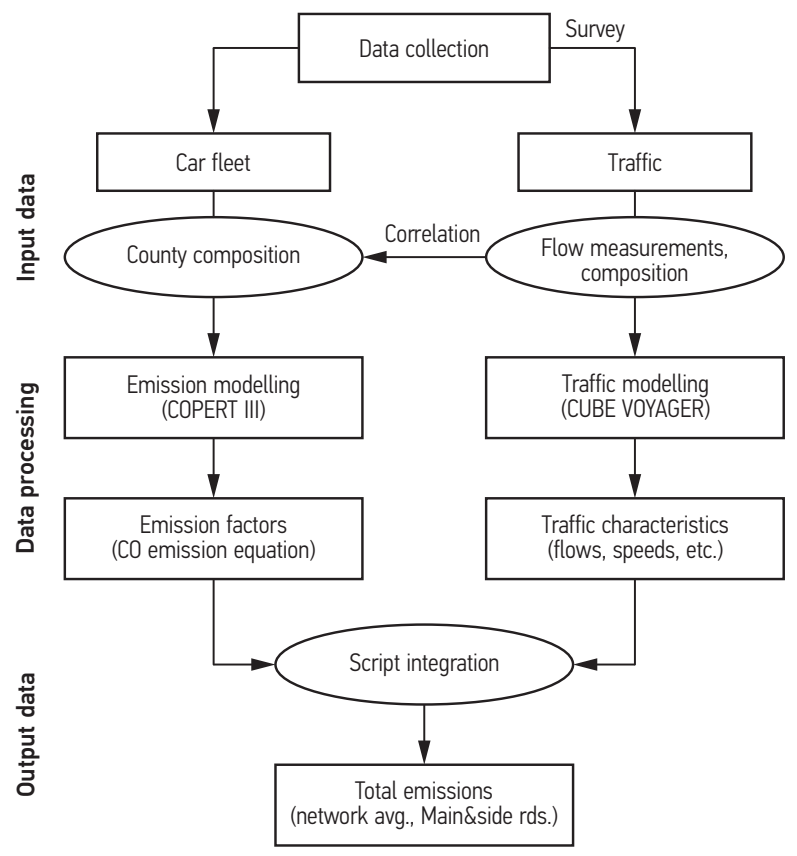

Fig. 1. Modelling approach
Basically, as seen in the Fig. 1, the modelling is conducted on two parallel approaches, i.e. emission modelling and traffic modelling. The final calculations are merging the outputs of the two sets of data to provide the total emissions.

\subsection{Problem Layout}

In Romania, the areas surrounding most large cities have essentially transformed over the last 20 years. With the fall of the communist regime in 1989, agricultural land was returned to its entitled owners, leading to chaotic residential plots sprawling outside from the cities without consideration for planning. Also, after joining the European Union in 2007, Romania's economy grew $5.7 \%$, and in the following year by $7.5 \%$, which drove to the increase of the residential construction sector by 29.3\% (Stutz 2009); meanwhile, the motorization rate increased $25.5 \%$ in a period of two years after adherence to the EU (Fig. 2), according to National Institute of Statistics (I.N.S.).

During the 1990's and towards to the present, given the proximity to the city of Cluj-Napoca the importance of Floreşti grew constantly. Its economic ascent led to real estate rapid development, which combined with lack of interest and commitment in land-use planning led to malfunctions in population mobility. In the following, we will come with arguments supporting the reasons for choosing Floreşti.

Floreşti is situated along the main national road E60 (Fig. 3), which connects Cluj-Napoca with the west of the country and with European Union. As reported by the Romanian National Company of Motorways and National Roads (CNADNR), in 2010 the annual average daily traffic between Cluj-Napoca and Florești counted more than 17000 vehicles. One reason for the high traffic volumes is Transylvania Motorway that acts as a bypass for the city of Cluj-Napoca, mainly diverging heavy traffic from transiting the city of Cluj-Napoca. There is still substantial amount of light transit traffic passing through Cluj-Napoca. As reported by CNADNR (in Romanian - Compania Națională de Autostrăzi şi Drumuri

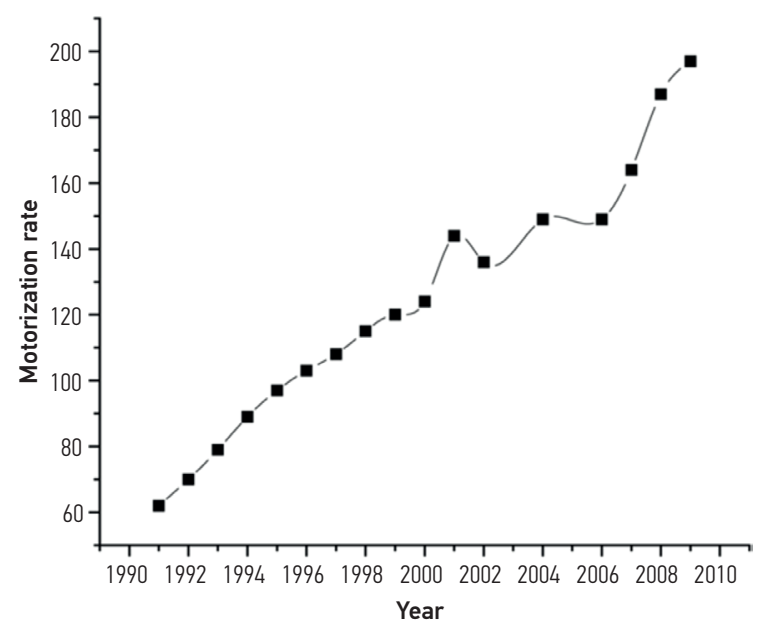

Fig. 2. Motorization rate evolution 


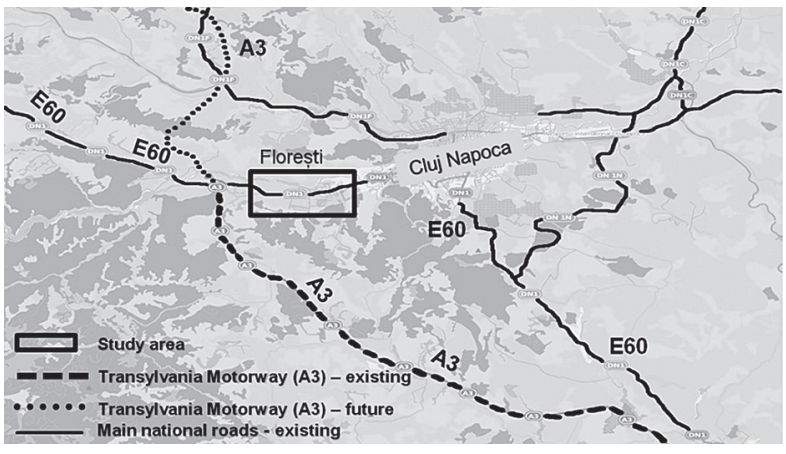

Fig. 3. Study area location

Naționale din România), it is estimated that in 2020 the annual average daily traffic between Cluj-Napoca and Transylvania Motorway will exceed 22000 vehicles.

The large private agricultural land in between ClujNapoca and Florești territorial administrations contributed to substantial economic and commercial investments, including one shopping mall, warehouses, vehicle sales, as well as residential individual housing facilities. In 2004, the national agency in charge of providing houses for young people built a 200 apartment residential neighborhood in the southern area of Floreşti.

Following this action, investment in housing went through a scale-up after 2007, due to profitability for constructing companies and individuals, encouraged by smaller local taxes, and banking credit policies. Unfortunately, the absence of a sustainable urban development plan in a period of three years the village has lost much of his identity and shape being possible to characterize it as an urban sprawl (Fig. 4). The southern area is characterized as ribbon development (Planning Policy Statement... 2010), causing fragmentation of the land. The area is without a continuous or uniform building line and has mostly blocks of apartments extending alongside roads, staggered or at angles to the road and with random gaps between. Vehicle access to the main road is poor due to lack of investments to road network in the last years.

We need to highlight that during the last years of development, no infrastructural investments attempted to solve the problems created by the growing land-use and traffic. Therefore, the only connection with ClujNapoca still remains the E60 national road.

Fig. 5 reveals the exponential evolution of the population registered in Floreşti in the last decade. According to census data, in 2007 there were 8605 people registered. The most recent unpublished population census from 2011 reveals that there are over 22000 people living in Floreşti and, taking into account the residential development that took place in the last 5 years, we assume that a population of more than 12000 people mostly settled in the southern region, are substantially commuting to the city of Cluj-Napoca.

The development in Florești has been mainly concerning mono-functional residential areas. The working places, services and other everyday needs are mainly lo-

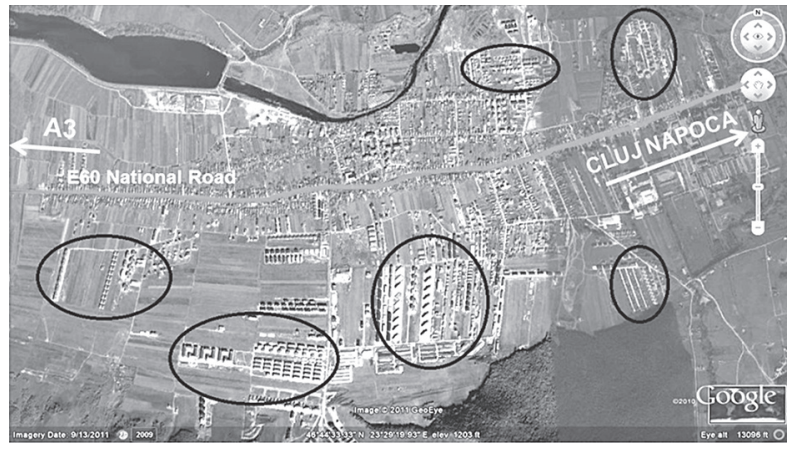

Fig. 4. Florești layout along E60 road (newly built areas are encompassed)

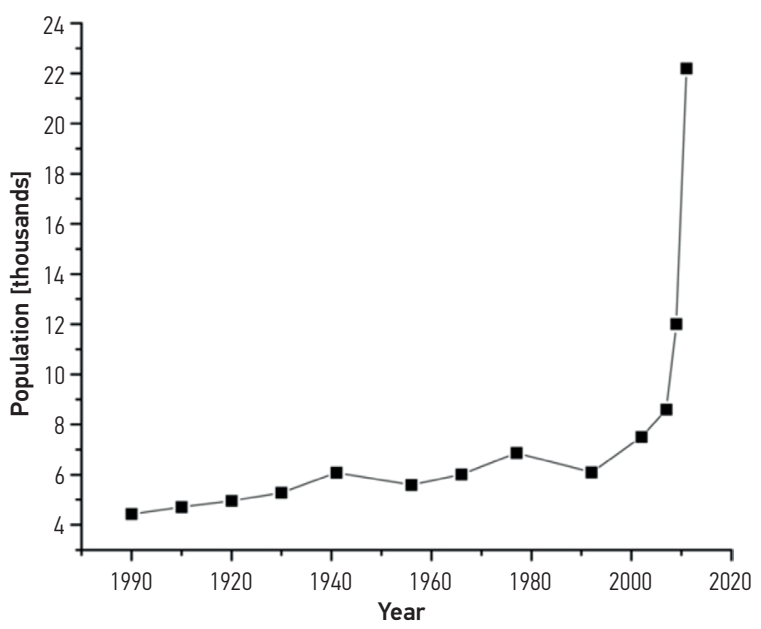

Fig. 5. Florești population growth in time

cated in Cluj-Napoca, thus creating large mobility needs for residents of Floreşti.

The main alternative to private car use - public transport - has not been developed in accordance to the growing populations' mobility needs. A private bus company provides transportation services for those who commute to Cluj-Napoca but the service is lacking accessibility (both distance-wise and considering safe and attractive pedestrian access to the bus stops, also access to tickets), sufficient frequency and is economically unattractive to the residents of Floreşti. Therefore, a more convenient alternative to get to the city is by personal vehicle. The situation is confirmed by the traffic counts described in the chapter 1.2 , as $98 \%$ of the counted vehicles are passenger cars or Light Duty Vehicles (LDV).

Due to the situation described above, we estimated that it would be useful to obtain detailed traffic characteristics in the satellite town, to analyse current trip patterns and to find solutions for a sustainable mobility plan to be developed in the future.

As shown in Fig. 1, we need two types of data for modelling. The first one is traffic data obtained through a survey associated with the second type of data that refers to car fleet composition. In the following sections, we will explain the data collection and analysis as well as the reasons for the adopted procedures. 


\subsection{Traffic Data Collection and Modelling}

The basic demand patterns across a network are described by the Origin-Destination (O-D) matrices. The matrix describes the pattern of travel in terms of trip movements across the network and between a set of origin points and a set of destination points (Taylor et al. 2000). As no such travel data is available concerning the study area, in order to get a clear image on traffic composition and volumes and for better understanding of traffic patterns, and later use it for traffic model calibration, a video recording survey was conducted on the morning of 20 December 2011, between 7:30 AM and 8:30 AM. Within this time interval, the traffic volume has a peak of the day due to the commuters, mainly from Floreşti to Cluj, so it can provide a worst case for the study. The reason for adopting this type of survey was the reduced size of the study area as well as some advantages that video survey gives to the traffic analyst and modeller (i.e. reanalyse video for different data sets).

As there is one main road passing through the town, the E60 national road, three characteristic locations were chosen for video recordings, namely at both entrances in the town (sections $\mathrm{A}$ and $\mathrm{C}$ ) and at the roundabout in the center (section B) as they appear in Fig. 6. The hourly traffic streams are shown for sections $\mathrm{A}$ and $\mathrm{C}$ in both directions of the traffic streams, as well as the flowing rates through the roundabout, in the bottom right panel highlighted in the figure. The videos were recorded simultaneously at all three locations and analysed afterwards by manually counting. The link average speed was determined by averaging the instantaneous speed profile as recorded by a Global Positioning System (GPS) device installed on a private passenger vehicle, which was driven at free flow speed on the streets of Floreşti. During the traffic survey, the same technique was used and the vehicle was driven along with the traffic stream on the main street.

We have to outline some aspects concerning the count distributions in section A and $\mathrm{C}$, as they resulted from the traffic survey. In section $\mathrm{A}$, the traffic flow that heads east towards Cluj-Napoca, follows the Poisson count distribution, while in section $\mathrm{C}$, in the same direction, a constant flow rate was identified. These count

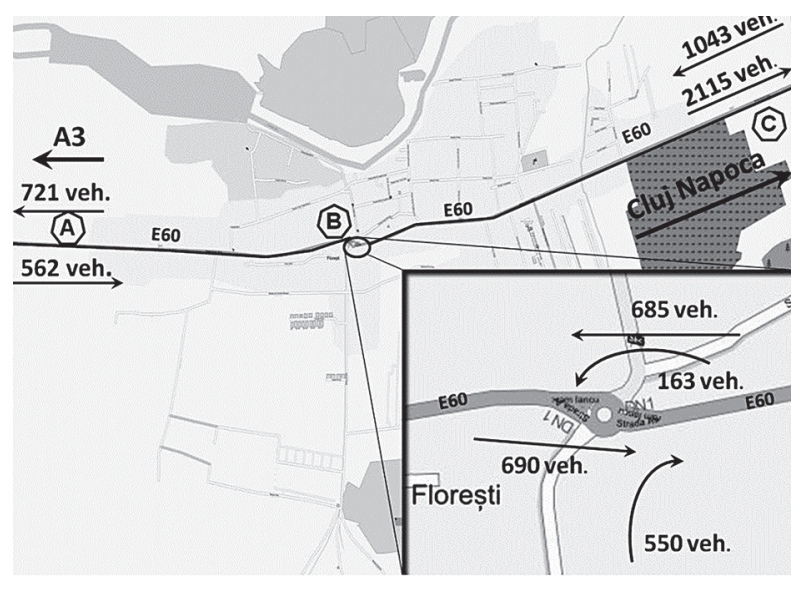

Fig. 6. Main hourly flow rates in surveillance sections distributions indicate the significant traffic volume produced in Florești and shifted towards Cluj-Napoca.

From the one hour total traffic count in the surveillance sections resulted on average, 98\% passenger vehicles together with LDV and only $2 \% \mathrm{HDV}$, including busses. As the present study refers to the CO emissions, in the following we will analyse and refer only to the $98 \%$ of all counted vehicles, therefore, our present modelling procedure deals with traffic volumes consisting of passenger cars and LDV's. If the present methodology is extended to other emissions, e.g. PM, the appropriate categories should be taken into account.

Models that simulate real world traffic flow are mostly used nowadays in road traffic planning. These models predict the effects of new infrastructures on the flows in a network, as well as identify areas of congestion following traffic predictions. The output data consists mainly of vehicle speeds and flows for given links (Nejadkoorki et al. 2008), as well as traffic volumes and time delays in the intersections. Traffic demands are coded in the form of origin-destination matrices, rows representing journey leaving zones and columns representing journey coming to zones. From the information we got from the survey, we began building the O-D matrix, by spreading the car trips in balance with residential density associated with land-use built environment. As official data about population spread distribution was not available, we used other methods, i.e. map lookup and parked car counting nearby the housing areas.

Macroscopic models represent travel movements with aggregate vehicle flows over a given time period. Interactions between individual vehicles are largely ignored. Macroscopic models are well suited to conduct wide-scale strategic policy testing that can relate to many aspects of travel demand, including land-use strategies, sociodemographic influences or destination choice (Holyoak, Stazic 2009). Therefore, macroscopic modelling was found suitable for this study, using the educational version of a well-known traffic modelling package, CUBE VOYAGER.

The traffic supply (network) in CUBE VOYAGER is coded and based upon information for intersections and individual roads. The Florești street network model consists out of 571 links, 276 intersections and 90 zones. The links have been described by the main characteristics, i.e. number of lanes, capacity, speed and travel time. The nodes of the network are described as yield or stopcontrolled priority intersections except one, which is a roundabout, located on the main road in Florești. There are no signal-controlled intersections within the range of the satellite town.

In order to validate the survey based $\mathrm{O}-\mathrm{D}$ matrix, we have used a widely used trip distribution approach, which is the gravity model, originally generated from an analogy with Newton's gravitational law. The gravity model estimates trips for each cell in the matrix, without using the observed trip pattern (Ortúzar, Willumsen 2011). The amount of travel between zones in the studied area was determined based on the relative attractiveness of the zones and accomplished through the trip distribution module in CUBE VOYAGER. The com- 
ponents of the gravity model used in CUBE VOYAGER were the productions and attractions of the zones, the skim matrix and the friction factors. The skim matrix can contain distance, travel times or generalized costs between all zone pairs. The friction factors were adjusted depending on the trip travel time distribution and they were adapted from the home-based-work repartition curve. After the adjustment of the friction factors, we considered calibration process accomplished when the difference between survey based O-D matrix and the one generated by the gravity model adopted fitted the 10\% difference (Wegmann, Everett 2003).

The calibrated gravity matrix is referred as the base scenario and the CUBE VOYAGER output represents the result from model run. As other commercial software packages, CUBE uses the network based upon Wardrop's second principle (Correa, Stier-Moses 2010) that considers, at equilibrium, same minimum cost of travel, for each origin-destination movement.

The outputs from CUBE indicate number of vehicles on the road, information on real (congested) speed, for each road in the network, as well as turning volumes and delays in the intersections. This data can serve as basis for additional models, i.e. fuel consumption or emission models, which can represent crucial factors in transportation planning.

\subsection{Car Fleet and Emission Factors Calculation}

As discussed in problem layout section regarding the data needed for the currently described modelling approach, in a second step of the data acquisition, Cluj County's car fleet composition was obtained from Romanian Automobile Register (R.A.R.) data for the reference year of 2011. The reason for not using the national car fleet composition is due to economic gaps that exist between different areas in Romania. These data were used to estimate the emission factors as described in the next section. We mention that the categories for which the emission factors were computed in COPERT III resemble the traffic composition, i.e. passenger cars and LDV's, as they result from the traffic survey.

In this paper, COPERT III, a widely used model to assess vehicle emissions from road transport, was

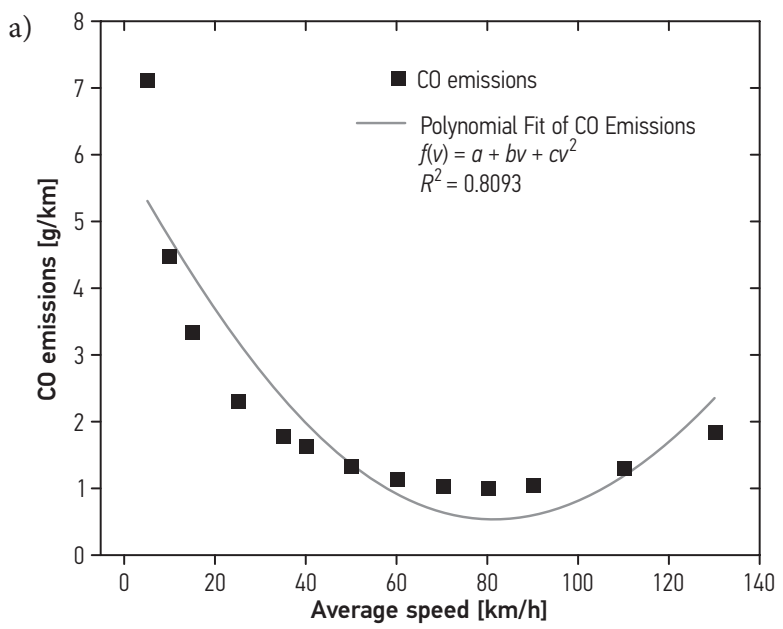

used to obtain the emission factors. There are three main types of vehicle emissions: hot, cold and evaporative. Hot emissions are produced after the engine has reached its working temperature and cold emissions are produced during warm up. The third type is evaporative loss and this comes from parts of a car other than exhaust emissions (the fuel tank, carburetor, fuel injection system) (Ntziachristos et al. 2009). In this current approach, we will not consider the evaporative losses.

The method to obtain the hot emission factors is presented in the following. As the emission factors depend on the vehicle average speed, we used as input data in COPERT III different average driving speeds, ranging from $5 \mathrm{~km} / \mathrm{h}$ to $130 \mathrm{~km} / \mathrm{h}$. Because of the traffic conditions modelled, the environment in which the vehicles are driving was set as the urban environment.

For a given speed $v$, the aggregated emission factor $F(V)$ is calculated as a weighted sum of the emission factors $F_{i}(V)$ at the same speed by the corresponding share $W_{i}$ of the vehicle type $i$ in the car fleet. In other words:

$$
F(V)=\sum_{i} W_{i} \cdot F_{i}(V)
$$

The results in Fig. 7 show that the aggregated emission factor for carbon monoxide has some dependence on the average travel speed considered. Seeking an analytical function for this dependence is important to further development our model. As recently reported (Rapone et al. 2008), for each vehicle type, there is a parabolic dependence of the individual emission factor on average driving speed. As seen also from Fig. 7a, a parabolic fit $f(v)=a+b \cdot v+c \cdot v^{2}$ gives the best fit with $a=5.946, b=-0.132, c=8.01 \cdot 10^{-4}$ and $R^{2}=0.8094$ that is not appropriate for the aggregated emission factor. Using the graphing and data analysis software package ORIGIN v8.6, the best fit was achieved by using a rational function (Fig. 7b), having the following expression:

$$
F(V)=\frac{1}{A+B \cdot V+C \cdot V^{2}},
$$

where: $A=0.045 ; B=0.02 ; C=-1.2 \cdot 10^{-4} ; R^{2}=0.9947$. In both functions, $v$ and $V$ represent the average speed in $\mathrm{km} / \mathrm{h}$, while the coefficients have appropriate dimensions to give emissions in $\mathrm{g} / \mathrm{km}$.

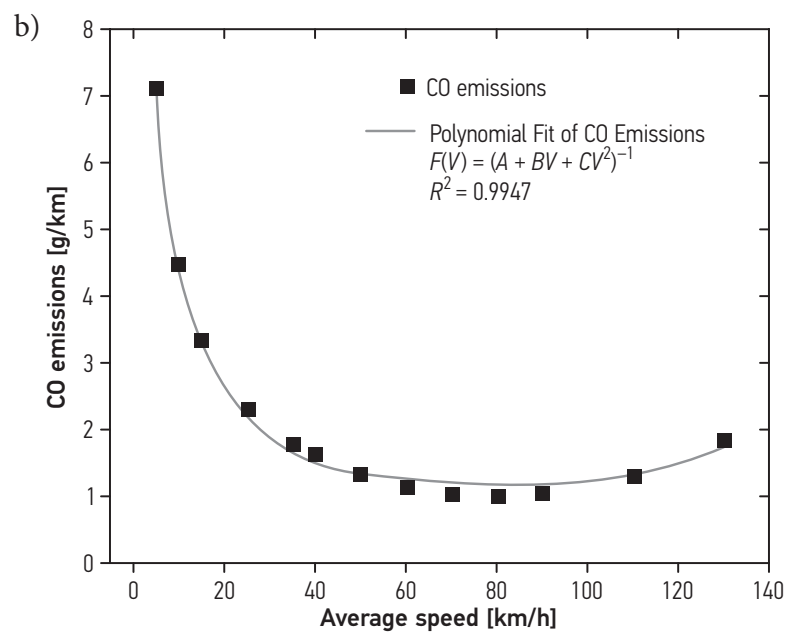

Fig. 7. Average speed dependant $\mathrm{CO}$ emissions and fitting functions 
One can observe that below the speed of $50 \mathrm{~km} / \mathrm{h}$, there is a good agreement between values exported from COPERT III and the fitting curve. Considering that the speed limit in urban areas in Romania is $50 \mathrm{~km} / \mathrm{h}$, the approximation might be a powerful tool for estimate emissions from road transport, for the considered car fleet. Between the speeds of 50 and $100 \mathrm{~km} / \mathrm{h}$, an interval in which the CO emissions are relatively low, the fitting function overestimates the emission factors, which might be an advantage in order to better approximate the real world driving conditions, even if those speeds will occur with low probability in our study. The overestimation by our fitting function is in agreement with the data reported by Rapone et al. (2008), in which the approximation of emission factors by a mean speed dependant second order polynomial regression emission equation recorded an underestimation compared to the alternative method's better predicted emission factors, as applied to experimental data.

We extracted the cold excess emissions from COPERT III, taking into consideration our traffic composition. COPERT outputs emission data, which depends on the monthly average temperature. Our calculation suggested that annual average aggregated cold emission excess factor for the considered car fleet composition was $0.83 \mathrm{~g}$ of $\mathrm{CO}$ per $\mathrm{km}$, as calculated with Equation 3:

$$
C(T)=\frac{\sum_{i} W_{i} \cdot F_{i}(T)}{12},
$$

where: $C(T)$ represents the annual average cold emission excess factor; $W_{i}$ is the share of the vehicle type $i$ in the car fleet; $F_{i}(T)$ is the individual cold emission excess factor that depends on the monthly average temperature $T$.

\subsection{Carbon monoxide emission calculation}

Taking into consideration the assumptions taken by $\mathrm{Ne}$ jadkoorki et al. (2008), we considered that due to the relative small size of Floreşti commune and its proximity to the city of Cluj-Napoca, most of the local trips would be short journeys. In addition, from the traffic simulation, we found out that the average trip length for the study area was $5.2 \mathrm{~km}$. According to Joumard and Sérié (1999), cold emissions for CO occur between 3 and $11.8 \mathrm{~km}$ of a vehicle's journey for an average speed of $18.8 \mathrm{~km} / \mathrm{h}$ and $48.1 \mathrm{~km} / \mathrm{h}$ respectively. Therefore, for the local trips starting within the simulation area (Ntziachristos et al. 2009), we assumed that cold start emissions occur. For these local trips, we added the average aggregated cold emission to the calculated average speed dependant hot emission, using CUBE's script that outputs total amount of $\mathrm{CO}$ emitted during the simulation. This is explained in Equation 4.

$$
Q_{C O}=(F(v)+C(T)) \cdot V_{\text {dist.tot }},
$$

where: $Q_{C O}$ represents the total amount of $\mathrm{CO}$ emissions in grams; $F(V)$ is the aggregated emission factor; $C(T)$ is the annual average cold emission excess factor; $V_{\text {dist.tot }}$ is the total vehicle-km traveled for the considered average speed.

Analyzing the traffic model, $37 \%$ out of the total number of vehicles had their zones of origin and destination outside the study area boundaries, so, taking into account the location of the traffic survey sections, there is a great uncertainty where is the traffic coming from and where is it heading towards after leaving the simulation area considered. For this reason, we assumed that the corresponding emissions are hot emissions and therefore, the average aggregated cold emissions were not considered in this case.

In order to test the practicability of the methodology developed, we have created a possible scenario taken into account by the local administration (Fig. 8). This involves the development of a new road that connects the southern region of the town with the city of ClujNapoca.

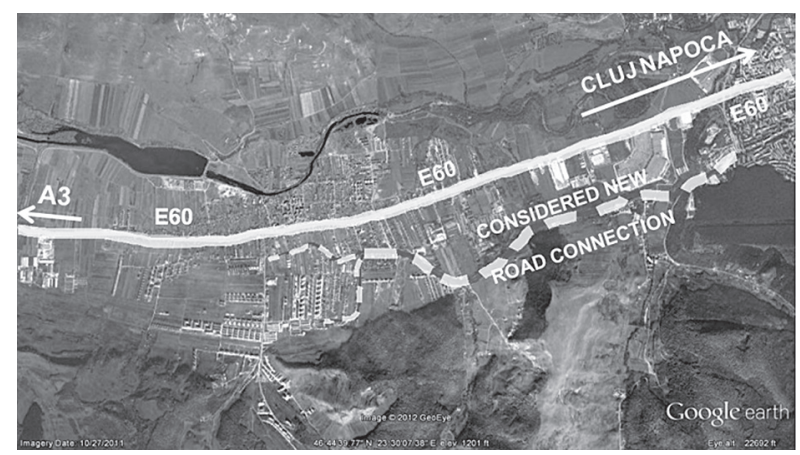

Fig. 8. Alternative scenario: development of a new road (in dashed line)

We have developed several modules in the traffic modelling software in order to obtain traffic characteristics that reveal the system performance regarding average network speed, average link speed as well as time delays in the intersections. Based on these modules and the aggregated emission equation determined previously, we computed the total emissions of $\mathrm{CO}$ for both base scenario and the alternative one. Table reveals the transportation network performance taking into account average travel speed and the related CO emissions, for both analysed scenarios.

The total turn delay in the intersections decreased with $11 \%$, i.e. from approximately $1.72 \mathrm{~min}$ per vehicle to about 1.53 minutes per vehicle, while the average trip increased slightly from $5.23 \mathrm{~km}$ to $5.27 \mathrm{~km}$.

As can be seen from the differences in $\mathrm{CO}$ emissions, the model is capable of taking into account the changes in the road network and driving conditions with the same fleet and the same time period, thus it is suitable tool for comparing different scenarios by emissions created by traffic in the network. As the COPERT III model is also suitable for modelling other emissions that are used in feasibility studies and cost-benefit analyses of transportation projects, the methodology is a suitable tool for creating input data for transportation planning. 
Table. Transportation system performance and related CO emissions (1 hour, morning peak) for base and proposed scenarios

\begin{tabular}{l|cc|cc|cc|cc}
\hline \multirow{2}{*}{ Scenario } & \multicolumn{2}{|c|}{ Network } & \multicolumn{2}{c|}{ Links } & \multicolumn{2}{c|}{ Main roads } & \multicolumn{2}{c}{ Side roads } \\
\cline { 2 - 11 } & $\begin{array}{c}\text { Avg. speed } \\
{[\mathrm{km} / \mathrm{h}]}\end{array}$ & $\begin{array}{c}\text { CO emissions } \\
{[\mathrm{g}]}\end{array}$ & $\begin{array}{c}\text { Avg. speed } \\
{[\mathrm{km} / \mathrm{h}]}\end{array}$ & $\begin{array}{c}\text { CO emissions } \\
{[\mathrm{g}]}\end{array}$ & $\begin{array}{c}\text { Avg. speed } \\
{[\mathrm{km} / \mathrm{h}]}\end{array}$ & $\begin{array}{c}\text { CO emissions } \\
{[\mathrm{g}]}\end{array}$ & $\begin{array}{c}\text { Avg. speed } \\
{[\mathrm{km} / \mathrm{h}]}\end{array}$ & $\begin{array}{c}\text { CO emissions } \\
{[\mathrm{g}]}\end{array}$ \\
\hline Base & 32 & 42517 & 38.9 & 38988 & 45.4 & 29743 & 22 & 9328 \\
\hline Proposed & 35.4 & 39944 & 42.9 & 36749 & 48.2 & 28349 & 27.5 & 8496 \\
\hline
\end{tabular}

\section{Modelling Critical Issues}

This section deals with probable source of errors in the assessment of traffic related CO. There have been no other local scale traffic pollutant emission estimates in the region of Cluj-Napoca and therefore we have no available data with which to compare our results. Nevertheless, both COPERT (Ntziachristos et al. 2009) and CUBE (Orru et al. 2008) have been widely used and validated through research and case studies regarding emission validation and traffic calibration, respectively. Therefore, we consider the calculation of $\mathrm{CO}$ emission parametric equation and the integration into the macroscopic model of Floreşti will stand for future methodologies in assessing traffic related pollutant emissions on a large scale.

The traffic model was built on traffic survey conducted in an inappropriate period of the year and therefore, the traffic volumes were not as high as expected. In addition, the lack of demographic and social data made us use basic trip generation procedures, based only on traffic survey and general assumptions on trips origins and destinations. This had also an impact on the modal split, as this modelling approach considered only personal vehicle and LDV traffic, without being able to predict the population share that will choose public transport.

Another issue refers to the COPERT III methodology, which is assumed to reflect real world conditions. The model is intended to evaluate the emission inventory of large road networks, where average speeds are obtained by traffic assignment models. COPERT III methodology cannot differentiate emission rates of trips with the same average speed, but with different speed profiles. The vehicle variations of instantaneous speed and acceleration have a major effect on emissions and consumption and COPERT methodology is not sensitive to such variations (Joumard et al. 1995). The real-world driving behavior introduces a slight level of uncertainty in estimating the $\mathrm{CO}$ emissions even when we use the emission factors calculated with the average travel speed on main roads and side roads only. COPERT III is being used by fewer parties, as the new version (COPERT IV) became widely used, resulting in differences in emission factors.

In the two scenarios, we note a significant difference between the network average speed related to $\mathrm{CO}$ emissions. The network average speed in this study is considered as the space mean speed, therefore it includes the time delays caused by queuing or by waiting time at an intersection. This phenomena is described by low speeds and idling engine. The COPERT methodol- ogy does not estimate emissions for speeds lower than $5 \mathrm{~km} / \mathrm{h}$, thus there is room for improving the accuracy of the modelling by complementing the methodology with estimation for idling emission in the future studies.

The car fleet data used in the study is relatively new (2011) with some vehicle categories not covered by the COPERT III methodology, but we considered that their share is insignificant, compared to the other prevailing categories.

\section{Interpretation of the Results}

Considering the results of the modelling and emission estimation, it is important to stress that the case of Floreşti and Cluj-Napoca is a typical example of urban sprawl with its typical consequences for the people travel demand, mobility, and transportation system. Therefore, the difference in the emissions between the two alternatives given in the Table 1 should not be taken as a proof of need to construct a new parallel road to satisfy the increasing demand of passenger car traffic (KahyaoğluKoračin et al. 2009).

The policy of passenger car demand satisfying (Mason, Nigmatullina 2011) proved to be costly to societies that experienced the motorization growth similar to what Romania had in the past 6 years (Fig. 2). The countries with high motorization rate adopted other approaches to deal with the problems of congestion; they focused on affecting mobility needs, investing in sustainable alternatives to personal car, implementing soft measures to support sustainable investments, etc. Investments to increase road infrastructure capacity was left as the last step to consider. As all the mentioned measures are based on analyses of different alternatives, the methodology developed and reported here can be a suitable tool to support sustainable transportation planning in Romania.

\section{Conclusions}

In conclusion, we presented a methodology to estimate traffic related pollutant emissions using integration of two modelling components: a transportation modelling software to predict reliable traffic flows, and an emission estimation procedure. In the following, we outline some of the main features of the proposed methodology:

1. The modelling approach is flexible and can be used for any other study site and for different sets of emitted pollutants with great impact on the environment and human health. The methodology can be applied by creating the traffic model and setting the aggregate emission equation based on the considered car fleet. 
The output data from the traffic and emission components can be used thereafter to obtain the emissions.

2. Due to the parametric equation, we can obtain a better approximation of traffic related emissions on a large scale, based on the average speed. The traffic modelling can be extended out of the peak-hour through whole day, allowing for the improvement of emission inventory reports.

3. The estimation of traffic related emissions can be done for any other regulated or unregulated pollutant. It is also possible to adjust the COPERT III model, depending on the composition of the car fleet in order to obtain the appropriate emissions for a certain area.

4. The developed methodology is a suitable tool to support analyzes for sustainable transport policies shedding light on possible differences between alternatives and scenarios.

\section{Acknowledgements}

The corresponding author acknowledges financial support from the project 'Doctoral studies in engineering sciences for developing the knowledge based society SIDOC' contract no. POSDRU/88/1.5/S/60078, project co-funded from European Social Fund through Sectorial Operational Program Human Resources 2007-2013.

\section{References}

Brown, A. L.; Affum, J. K. 2002. A GIS-based environmental modelling system for transportation planners, Computers, Environment and Urban Systems 26(6): 577-590. http://dx.doi.org/10.1016/S0198-9715(01)00016-3

Correa, J. R.; Stier-Moses, N. E. 2010. Wardrop Equilibria, in Wiley Encyclopedia of Operations Research and Management Science. http://dx.doi.org/10.1002/9780470400531.eorms0962

Fenger, J. 1999. Urban air quality, Atmospheric Environment 33(29): 4877-4900. http://dx.doi.org/10.1016/S1352-2310(99)00290-3

Flachsbart, P. G. 1999. Human exposure to carbon monoxide from mobile sources, Chemosphere - Global Change Science 1(1-3): 301-329. http://dx.doi.org/10.1016/S1465-9972(99)00030-6

Holyoak, N.; Stazic, B. 2009. Benefits of linking macro-demand forecasting models and microsimulation models, ITE Journal 79(10): 30-32, 37-39.

Joumard, R.; Jost, P.; Hickman, J. 1995. Influence of instantaneous speed and acceleration on hot passenger car emissions and fuel consumption, SAE Technical Paper 950928. http://dx.doi.org/10.4271/950928

Joumard R.; Sérié E. 1999. Modelling of Cold Start Emissions for Passenger Cars. INRETS report LTE 9931. 86 p. Available from: http://www.inrets.fr/ur/lte/cost319/MEETDeliverable08.pdf

Kahyaoğlu-Koračin, J.; Bassett, S. D.; Mouat, D. A.; Gertler, A. W. 2009. Application of a scenario-based modeling system to evaluate the air quality impacts of future growth, Atmospheric Environment 43(5): 1021-1028. http://dx.doi.org/10.1016/j.atmosenv.2008.04.004

Mason, R. J.; Nigmatullina, L. 2011. Suburbanization and sustainability in metropolitan Moscow, Geographical Review 101(3): 316-333. http://dx.doi.org/10.1111/j.1931-0846.2011.00099.x
Nejadkoorki, F.; Nicholson, K.; Lake, I.; Davies, T. 2008. An approach for modelling $\mathrm{CO}_{2}$ emissions from road traffic in urban areas, Science of the Total Environment 406(1-2): 269-278. http://dx.doi.org/10.1016/j.scitotenv.2008.07.055

Ntziachristos, L; Gkatzoflias, D.; Kouridis, C.; Samaras, Z. 2009. COPERT: a European road transport emission inventory model, in Information Technologies in Environmental Engineering: Proceedings of the 4th International ICSC Symposium Thessaloniki, 28-29 May 2009, Greece, 491-504. http://dx.doi.org/10.1007/978-3-540-88351-7_37

O’Donoghue, R. T.; Broderick, B. M.; Delaney, K. 2007. Assessing the impacts of infrastructural road changes on air quality: a case study, Transportation Research Part D: Transport and Environment 12(8): 529-536.

http://dx.doi.org/10.1016/j.trd.2007.07.009

Orru, H.; Kaasik, M.; Antov, D.; Forsberg, B. 2008. Evolution of traffic flows and traffic-induced air pollution due to structural changes and development during 1993-2006 in Tartu (Estonia), The Baltic Journal of Road and Bridge Engineering 3(4): 206-212. http://dx.doi.org/10.3846/1822-427X.2008.3.206-212

Ortúzar, J. D.; Willumsen, L. G. 2011. Modelling Transport. 4th edition. Wiley. $606 \mathrm{p}$.

Planning Policy Statement 21: Sustainable Development in the Countryside. 2010. Department of Environment (Northern Ireland) United Kingdom. 44 p. Available from Internet: http://www.planningni.gov.uk/index/policy/policy_publications/planning_statements/planning_policy_statement_21_pps21__sustainable_development_in_the_ countryside-3.pdf

Rapone, M.; Prati, M. V.; Costagliola, M. A.; Ragione, L. D.; Meccariello, G. 2008. Emission factors determination of Euro III 1,200- to 1,400-cc petrol passenger cars with a PLS multivariate regression model, Environmental Modeling \& Assessment 13(3): 383-392. http://dx.doi.org/10.1007/s10666-007-9108-4

Saija S.; Romano, D. 2002. A methodology for the estimation of road transport air emissions in urban areas of Italy, Atmospheric Environment 36(34): 5377-5383. http://dx.doi.org/10.1016/S1352-2310(02)00488-0

Stutz, B. 2009. The new urbanists: tackling Europe's sprawl, Yale Environment 360. Available from Internet: http://e360. yale.edu/content/feature.msp?id=2118

Taylor, M. A. P.; Bonsall, P. W.; Young, W. 2000. Understanding Traffic Systems: Data, Analysis, and Presentation. 2nd edition. Ashgate Pub Ltd. 456 p.

Wegmann, F.; Everett, J. 2003. Minimum Travel Demand Model Calibration and Validation Guidelines for State of Tennessee. Available from Internet: http://web.utk.edu/ tnmug08/ misc/valid.pdf 